\title{
Dialysis and photo-electrodialysis processes using new synthesized polymeric membranes for the selective removal of bivalent cations
}

\author{
S. BENSAADI ${ }^{1}$, N. NASRALLAH ${ }^{2}$, A. AMRANE ${ }^{3}$, M. TRARI ${ }^{4}$, H. KERDJOUDJ ${ }^{1}$,
} O. AROUS', M. AMARA ${ }^{1}$

1 Laboratoire d'Hydrométallurgie et Chimie Inorganique Moléculaire, Faculté de Chimie, USTHB, BP 32 ElAlia, Bab Ezzouar, Algiers, Algeria

${ }^{2}$ Laboratoire de Génie de la Réaction, Faculté de Génie Mécanique et Génie des Procédés, USTHB, BP 32 ElAlia, Bab Ezzouar, Algiers, Algeria

${ }^{3}$ Ecole Nationale Supérieure de Chimie de Rennes, Université de Rennes 1, CNRS, UMR 6226, Rennes, Avenue du Général Leclerc, CS 50837, 35708 Rennes Cedex 7, France

${ }^{4}$ Laboratoire de Stockage et de Valorisation de L'Energie Solaire, Faculté de Chimie, USTHB, Algiers, Algeria 


\section{Graphical abstract}

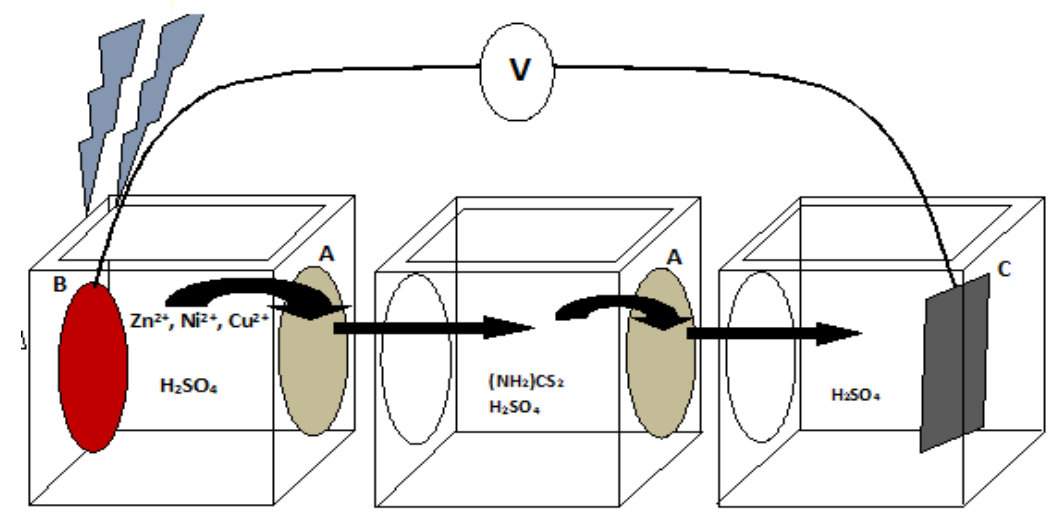

\section{Highlights}

- New homogeneous Polymer Inclusion Membranes (PIM) containing polyelectrolytes have been synthesized.

- Photo-electro-reduction of $\mathrm{Ni2}+, \mathrm{Zn} 2+$ and $\mathrm{Cu} 2+$ as metals has been carried out using a hybrid-system FeAl2O4 electrode /membrane/platinum electrode.

- $\mathrm{FeAl}_{2} \mathrm{O}_{4}$ is low cost, has environmentally friendly characteristic

- $\mathrm{FeAl}_{2} \mathrm{O}_{4}$ absorbs over the whole solar spectrum.

Abstract: Polymer inclusion membranes (PIM) have emerged as a new technique for the ions selective separation. In this work, a novel class of membrane for the separation of $\mathrm{M}^{2+}$ ions (= $\mathrm{Ni}^{2+}, \mathrm{Cu}^{2+}$ and $\mathrm{Zn}^{2+}$ ) coupled with photo-electrodialysis was developed. The membrane was polymerized from cellulose triacetate (CTA) and other polymers (PVP, PEI or PEG), tri-ethyl hexyl phosphate (TEHP) was incorporated in the membrane as a plasticizer. The cellulose plasticized membranes were characterized by FTIR spectroscopy, scanning electron microscopy (SEM) and thermal analysis (TGA). Photoelectro-dialysis was performed under visible light. The $\mathrm{M}^{2+}$ transport across combined PIM with photo-electrode $\mathrm{Fe} \mathrm{Al}_{2} \mathrm{O}_{4}$ showed acceptable ions transport efficiency (33\% after $3 \mathrm{~h}$ ). The spinel oxide semi-conductor $p$ $\mathrm{FeAl}_{2} \mathrm{O}_{4}$ prepared from nitrates decomposition was synthesized by chemical route and 
characterized by X-ray diffraction (XRD). It absorbed over the whole solar spectrum, it is low cost, non-toxic and exhibited a chemical stability over a wide $\mathrm{pH}$ range.

Key words: photoelectro-dialysis; Membrane, Polymer, $\mathrm{FeAl}_{2} \mathrm{O}_{4}$, Metals.

\section{Introduction}

The rapid industrial development, depleting energy resources and growing concern for the environment safety have put an increasing demand to enhance the efficiency of existing technologies. The exploration of new sources of raw materials and the development of novel alternatives that allow the water treatment as well as the recuperation of valuable and toxic materials has become an obligation.

In this context, membrane technology provides solutions to some of these problems [1] and the ions exchange technology allows the concentration of metals. Novel membranes have been developed by introducing new compounds and/or by modifying their surface yielding the separation between anions or cations with mixed valences [2-5]. A new generation of ion exchange membranes can be prepared by changing the hydrophilic and/or the hydrophobic balance. These types of membranes permit the separation between ions of the same valence [6].

Most of the conventional separation and concentration processes used in hydrometallurgy, like precipitation, ion exchange on resins or liquid-liquid extraction [7-10], are today reconsidered from the point of view of their possible substitution by new strategy using synthetic membranes. Recently, a novel type of liquid membrane called polymer inclusion membrane (PIM) was developed to provide metal ion transport with high selectivity, as well as an easy setup [11]. PIMs offer a great potential for industrial separations over other membrane types. Amara et al. studied previously a combination between membrane selectivity and photo-electrochemistry using commercial cation exchange membrane (noticed CRA) and Cadmium Sulfate (CdS) as photo electrode for the separation and recovery of some metallic ions $\left(\mathrm{Cu}^{2+}, \mathrm{Zn}^{2+}\right.$ and $\left.\mathrm{Ni}^{2+}\right)$ in aqueous medium [12]. The authors observed that illuminated $n$-CdS electrode leads to an increase of the transport flux at least 10 times more than that obtained in the dark. A polymeric membrane obtained by the combination of cellulose triacetate and poly-4-vinylpyridine in the presence of $n-\mathrm{Bi}_{2} \mathrm{~S}_{3}$ as photoelectrode has been used by the same authors showing an important affinity either for anionic species or cationic species depending on the composition of the solution [13]. The 
transport of lead and cadmium ions in two different membrane systems PIM and PIM coupled with photo electrode using Tri-Butyl phosphate (TBP) as organo-phosphorous carrier and 2nitro phenyl octyl ether (NPOE) as plasticizer have been investigated and the results were compared to commercial cation exchange membranes [14-16]. More recently, a novel class of PIM using a mixture of polymer and polyelectrolytes has been developed [17]. A comparative study of the transport across PIM modified by two semi-conductors namely $p-\mathrm{CuFeO}_{2}$ type and $n-\mathrm{WO}_{3}$ showed that the cadmium deposition is significantly increased when using modified PIM by the photo-electrodes in $n / p$ configuration.

A variety of oxides with new band structures were considered as optically active materials [18]. The spinels $\mathrm{FeM}_{2} \mathrm{O}_{4}(\mathrm{M}=3 d$ metal $)$ have received a growing attention in photocatalysis because of the $\mathrm{pH}$-insensitivity of the electronic bands and optical properties permitting the exploitation of the solar spectrum [19].

The semiconductor is an essential element of photo electrochemical (PEC) device and in order to approach the problem systematically, we have chosen an oxide with a new band structure. Among oxides, the spinel $\mathrm{FeM}_{2} \mathrm{O}_{4}$, where $\mathrm{M}$ is commonly a $3 \mathrm{~d}$ metal, have not received a great interest although they possess a forbidden band with $d-d$ photo transitions and have relatively large absorption coefficients [20].

$\mathrm{FeAl}_{2} \mathrm{O}_{4}$ is a mixed oxide normal spinel, where one eighth of the tetrahedral sites is occupied by $\mathrm{Fe}^{2+}$ cations and one half of the octahedral sites are occupied by $\mathrm{Al}^{3+}$ cations. Sometimes, depending on the synthetic process, the $\mathrm{Fe}^{2+}$ cations can also occupy octahedral sites [21]. $\mathrm{FeAl}_{2} \mathrm{O}_{4}$ provides an excellent combination of physical and chemical properties. It has high ductility (fracture-mechanical strength) and flexibility against cracking and spalling. However, reports on this spinel compound are scarce especially those dealing with its magnetic behavior [22-24].

The present work deals with two attractive aspects, energetic (solar energy) and environmental based on the membrane selectivity for metal ions. New polymeric membranes based on a mixture of CTA and poly-electrolytes plasticized by tris ethylhexyl phosphate were synthesized. The membranes $(\mathrm{CTA}+$ poly-electrolyte + plasticizer $)$ were characterized by Fourier Transform Infrared (FTIR), scanning electron microscopy (SEM) and Thermogravimetric Analysis (TGA). As application, the photo electro-dialysis of solutions containing copper, zinc and nickel was studied; thereby, opening new pathways to fabricate hybrid systems dedicated to environmental protection. The membrane was combined with a photoelectrode $\mathrm{FeAl}_{2} \mathrm{O}_{4}$, with the aim of increasing the photon-to current yield by minimizing the loss of electron/hole $\left(\mathrm{e}^{-} / \mathrm{h}^{+}\right)$pairs by recombination. $\mathrm{FeAl}_{2} \mathrm{O}_{4}$ has environmentally friendly 
characteristics and absorbs over the whole solar spectrum. Moreover, it has a conduction band of $3 d$ parentage with a high reducing capacity able to reduce the $\mathrm{M}^{2+}$ ions into their elemental states.

\section{Materials and Methods}

\subsection{Chemicals}

Copper (II) nitrate, zinc (II) nitrate, nickel (II) nitrate, chloroform, cellulose triacetate (CTA), polyvinylpyrrolidone (PVP), polyethylenimine (PEI) and polyethylenglycol (PEG) were analytical grade reagents purchased from Fluka. Tris ethylhexyl phosphate (TEHP) (GC $\geq 98 \%$ ) was a product of Merck Company. The aqueous solutions were prepared by dissolving the different reagents in bi-distilled water $(\sim 1 \mathrm{M} \Omega \mathrm{cm})$.

\subsection{Membrane preparation}

PIMs were prepared using the same procedure described by Sugiura et al. [25-27]. Briefly, $0.2 \mathrm{~g}$ of CTA and $0.1 \mathrm{~g}$ of polyelectrolyte were dissolved in $20 \mathrm{~mL}$ of chloroform and stirred for $4 \mathrm{~h}$. Then, $0.1 \mathrm{~mL}$ of TEHP was added to the mixture and maintained $2 \mathrm{~h}$ under vigorous stirring. The homogeneous solution obtained was poured into a $9 \mathrm{~cm}$ diameter glass petri dish and left to evaporate slowly during 24 hours. The resulting membrane was extracted, after evaporation of solvent, by addition of water and dried at $40^{\circ} \mathrm{C}$.

\subsection{Characteristics of CMS commercial membrane:}

The physical and chemical characteristics of the commercial membrane used in dialysis are reported in the Appendix.

\subsection{Synthesis of the semi-conductor $\mathrm{FeAl}_{2} \mathrm{O}_{4}$}

The spinel $\mathrm{FeAl}_{2} \mathrm{O}_{4}$ was developed by the nitrate route, $\mathrm{Fe}\left(\mathrm{NO}_{3}\right)_{2} .9 \mathrm{H}_{2} \mathrm{O}$ (Merck, 99\%) and $\mathrm{Al}\left(\mathrm{NO}_{3}\right)_{3} .9 \mathrm{H}_{2} \mathrm{O}$ (Merck, 99.5\%) were accurately weighed, dissolved in a nitric solution (volumetric ratio $\mathrm{HNO}_{3}(65$ wt. $\%) / \mathrm{H}_{2} \mathrm{O}=1 / 3$ ) and slowly evaporated on a sand bath. The amorphous precipitate was denitrified on a magnetic hot plate. The powder was homogenized in an agate mortar and sintered at $950^{\circ} \mathrm{C}$; the phases were identified by $\mathrm{X}$-ray diffraction (XRD) using $\mathrm{Cu} \mathrm{K \alpha}$ anticathode. For photo electrochemical (PEC) characterization, the powder was cold pressed under $5 \mathrm{kbar}$ into $13 \mathrm{~mm}$ diameters discs of $1 \mathrm{~mm}$ thickness and sintered at $900^{\circ} \mathrm{C}$. The density of the sample was found to be $90 \%$ of the theoretical bulk value and the mechanical properties were acceptable. 


\subsection{Characterization of $\mathrm{FeAl}_{2} \mathrm{O}_{4}$}

$\mathrm{FeAl}_{2} \mathrm{O}_{4}$ exhibited a brick red color with homogeneous morphology. The XRD pattern was free of the starting oxides and revealed the existence of a pure spinel phase. All peaks were indexed in a cubic symmetry (space group $\mathrm{Fd} 3 \mathrm{~m}$ ) with a lattice constant of $0.8441 \mathrm{~nm}$ in agreement with the JCPDS card $\mathrm{N}^{\circ} 22-1012$.

The size crystallite $(\sim 40 \mathrm{~nm})$ is evaluated from the full with at half maximum ( $\beta, \mathrm{rad})$ of the most intense (311) XRD spectrum, according to the empirical relationship [31].

$$
d=\frac{0.94 \lambda}{\beta \cos \theta}
$$

$\Lambda(=1.54178 \AA)$ is the wavelength of the copper anticathode and $\theta$ (rad) the diffraction angle. The specific surface area $\left(S_{\mathrm{sp}}\right)$ of the oxide is defined by the ratio of the surface of the crystalline particle assumed to be spherical.

With: $\quad \mathrm{S}_{\mathrm{sp}}=\frac{\mathrm{S}}{\mathrm{m}}=\frac{4 \pi \mathrm{r}^{2}}{\rho_{\exp } \cdot \frac{4}{3} \pi \mathbf{r}^{3}}=\frac{3}{\rho_{\exp } \mathbf{r}}$

$$
S_{\mathrm{sp}}=\frac{6}{\rho_{\exp } \mathbf{d}}
$$

Where $\rho_{\text {ex }}$ is the experimental density $\left(\mathrm{kg} / \mathrm{m}^{3}\right)$ and $r$ the particle radius $(\mathrm{m})$.

The particle of photo-catalyst was equivalent to a sphere of radius $r$. According to the calculations of the lattice parameter $a$, it was found that the solid has a cubic spinel structure. The density of the photo-catalyst was calculated from the following relationship:

$$
\rho_{\text {exp }}=\frac{M}{V}=\frac{8 M}{N_{\cdot} \mathbf{a}^{3}}
$$

$N$ is the Avogadro's number, and $\mathrm{M}$ the molecular weight and $\mathrm{V}$ the volume of the unit cell. The corresponding results are collected in Table 1.

\subsection{Analysis}

The FTIR spectra were recorded with a Perkin-Elmer spectrometer (Spectrum One). The morphologies of the different membranes were determined by SEM analysis using a JEOL JSM 6301F-FEG. The thermo-gravimetric analyses (TGA) were achieved using a TGA Q500, TA Instrument, programmed from 50 to $600^{\circ} \mathrm{C}$ at a rate of $10^{\circ} \mathrm{C} / \mathrm{min}$ under nitrogen atmosphere. 
The $\mathrm{M}^{2+}$ concentration was determined by atomic absorption using a Perkin-Elmer 2380 spectrometer (air/acetylene flame). The wavelengths used for the determination of $\mathrm{Cu}, \mathrm{Zn}$ and Ni were 324.8, 213.9 and $232 \mathrm{~nm}$, respectively. A digital pH meter Cyberscan 500 was used to accurately measure the $\mathrm{pH}$.

\subsection{Closed cell device}

Figure 1 shows schematically the principle of the closed cell device with the capacity of the different compartments. Three independent experiments were realized to determine the metallic ions concentration; the experimental standard deviation was determined to be $\pm 5 \%$.

\subsection{Photo-electrodialysis using (CTA + PEI + TEHP) membrane noted M1}

Photo-electrodialysis was performed under visible light using a tungsten lamp (200 W, Osram). The polarization of the photo-electrode, when connected to the inert counter electrode (stainless steel) generates an electric field through the cell containing the membranes. The same cell and the same membrane M1 were used. The open cell used in this work is illustrated in Figure 2.

\section{Results and discussion}

\subsection{Physical characterization of the synthesized membranes}

The characteristics of the membrane synthesized from CTA polymer and polyelectrolytes (PEI, PEG and PVP) are gathered in Table 2. As the plasticizer molecules are hydrophobic, the location of TEHP on the surface and in the volume of the modified membranes changes the contact angle which is an indicative parameter of the wetting character of the material. The results indicate that all synthesized membranes were amorphous PIMs whose physical properties were modified. The plasticizer TEHP is hydrophobic and hence caused the elevation of the contact angle of the synthesized membranes $\left(\theta=46^{\circ}\right.$ in the case of hydrophilic CTA membrane and $\theta=\sim 76^{\circ}$ in the case of hydrophobic CTA-TEHP membrane). This value decreased in the case of (CTA+ PEI+ TEHP) and (CTA+ PVP+ TEHP) membranes because PEI, PVP and PEG are hydrophilic polyelectrolytes.

\subsection{FTIR characterization}

Figures 3a-c show the FTIR spectra of the three synthesized membranes. The main feature of the spectrum of (CTA + PEI + TEHP) membrane was the absorption band around 
$1755 \mathrm{~cm}^{-1}$, attributed to stretching vibrations of the carbonyl group. The bands at 1246 and $1032 \mathrm{~cm}^{-1}$ corresponded to stretching modes of symmetric and asymmetric $\mathrm{C}-\mathrm{O}$ single bonds respectively. Less intense bands at 2960-2932 and $2870 \mathrm{~cm}^{-1}$ can be ascribed to $\mathrm{C}-\mathrm{H}$ bonds, while the wide band observed at $3475 \mathrm{~cm}^{-1}$ was due to the $\mathrm{N}-\mathrm{H}$ bond stretching modes. The spectra of (CTA + PEG + PVP + TEHP) and (CTA + PVP + TEHP) membranes showed the same bands with further ones at 1659 and $1665 \mathrm{~cm}^{-1}$, assigned to the stretching modes of $\mathrm{C}=\mathrm{C}$ bonds of $\mathrm{PVP}$ and $\mathrm{PEG}$.

\subsection{Characterization by SEM}

SEM characterization is used to assess the effect of additives on the membranes morphology [28-30]. SEM images of M1, M2 and M3 membranes are given as surface section $(1 \mu \mathrm{m})$ in Figures 4a-c, respectively.

From SEM images, it can be observed that the morphologies of the (polymer + polyelectrolyte + plasticizer) membranes had a uniform surface and appeared dense with no apparent porosity. We remark also that the hybrid membranes exhibited still homogeneous sponge microstructures. These observations confirm the results of the contact angle.

\subsection{Characterization by thermo-gravimetric analysis (TGA)}

Thermal gravimetric analysis (TGA) is a method of thermal investigation in which changes in physical and chemical properties of materials are measured as a function of increasing temperature (with constant heating rate). TGA is commonly used to determine selected characteristics of materials that exhibit either mass loss or gain due to decomposition, oxidation, or loss of volatiles component (such as solvent and plasticizer).

The TGA experiments were done using TA Instrument equipment at a scanning speed of $10{ }^{\circ} \mathrm{C} \mathrm{min}^{-1}$. Figures 5a-c show the TGA thermal behaviors of M1, M2 and M3 membranes, respectively.

Based on Figure 5a, the following observation can be made: (CTA + PEI + TEHP) membrane was thermally degraded in three steps. The first one at $155{ }^{\circ} \mathrm{C}$ represented the volatilization of TEHP. The second and third steps, at 280 and $390{ }^{\circ} \mathrm{C}$, represent a degradation of polyethylenimine (PEI) and cellulose triacetate (CTA) respectively. It must be noted that the volatilization of TEHP started before its boiling point $\left(215{ }^{\circ} \mathrm{C}\right)$ meaning that TEHP has interacted with CTA and PEI polymers. (CTA + PEG + PVP + TEHP) membrane degraded in two steps (Figure 5b). The first one at $180^{\circ} \mathrm{C}$ represented the volatilization of 
TEHP. The second step, at $350{ }^{\circ} \mathrm{C}$, represented a degradation of different polymers (CTA, PEG, PVP).

$(\mathrm{CTA}+\mathrm{PVP}+\mathrm{TEHP})$ membrane degraded also in two steps (Figure 5c). The first one at $186{ }^{\circ} \mathrm{C}$ corresponded to the volatilization of TEHP. The second step, at $323{ }^{\circ} \mathrm{C}$, represented a degradation of CTA and PVP polymers. The results obtained with M2 and M3 confirmed the presence of specific interactions between the different polymers.

\subsection{Transport of $\mathrm{M}^{2+}$ ions using synthetic membranes}

All synthesized membranes were used for the selective transport of bivalent ions $\mathrm{M}^{2+}$, the three membranes contained the same basis polymer (CTA) and the same plasticizer (TEHP); the difference was the polyelectrolyte nature (PEI, PEG, PVP).

\subsubsection{Amount of metal transferred (titration in Compartment 2).}

The cell used for Dialysis experiments consisted of three compartments, made of Teflon with a maximum filling volume of $100 \mathrm{~mL}$, separated by the synthesized membranes. The feed compartment contained a mixture of $\mathrm{M}^{2+}$ ions $\left(=\mathrm{Cu}^{2+}, \mathrm{Zn}^{2+}\right.$ and $\left.\mathrm{Ni}^{2+}\right)$ at a concentration of $10^{-2} \mathrm{~mol} \mathrm{~L}^{-1}$ of the metal salt $\left(3.33 \times 10^{-3} \mathrm{~mol} \mathrm{~L}^{-1}\right.$ for each metal); the second compartment contained thiourea $\mathrm{CS}\left(\mathrm{NH}_{2}\right)_{2}$ and $\mathrm{H}_{2} \mathrm{SO}_{4}\left(0.5 \mathrm{~mol} \mathrm{~L}^{-1}\right)$; the third compartment was filled with only $\mathrm{H}_{2} \mathrm{SO}_{4}\left(0.5 \mathrm{~mol} \mathrm{~L}^{-1}\right)$ solution. The use of thiourea should enhance the selectivity according to a chelation effect toward metals [32]. It is soluble in water but not in organic solvents and presents basic properties due to the electron distinct pairs of sulfide and nitrogen atoms. These electron pairs give thiourea a complexation capacity especially towards heavy metals. According to the Lewis structure, the coordination can be affected by the nitrogen atoms or sulfur atoms.

Figures 6a-c show the variation of the $\mathrm{M}^{2+}$ concentrations in the first receiving compartment according to the dialysis duration. We note that the efficiency and the selectivity of the transferred $\mathrm{M}^{2+}$ ions depend on the membrane nature.

In the case of the membrane M1, the transferred amount displays the following order: $\mathrm{Ni}^{2+}>\mathrm{Zn}^{2+}>\mathrm{Cu}^{2+}$. The amount of $\mathrm{Cu}^{2+}$ transferred to the second compartment appeared insignificant and this can be due to the two main reasons: i) $\mathrm{Cu}^{2+}$ competes with $\mathrm{Ni}^{2+}$ and $\mathrm{Zn}^{2+}$ which is not at all in favor of this latter ii) $\mathrm{Ni}^{2+}$ is fully and rapidly transferred from the second to the third compartment. The same findings were also observed with the two other membranes. In the case of $\mathrm{Zn}^{2+}$, the concentration in the compartment 2 decreased during $3 \mathrm{~h}$, 
suggesting that it continues to be transferred to the third compartment. The beginning of the $\mathrm{Ni}^{2+}$ and $\mathrm{Zn}^{2+}$ transfer through the membrane M2 was observed after $2 \mathrm{~h}$ of dialysis.

\subsubsection{Amount of metal transferred (titration in compartment 3)}

Figures 7a-c illustrate the variation of concentrations in the compartment 3 using the three synthesized membranes M1-M2-M3. It can be seen that $\mathrm{Cu}^{2+}$ failed to cross the three membranes. This can be explained by the low selectivity for $\mathrm{Cu}^{2+}$ and the binding within the membrane through complexation with the nitrogen atoms of PEI and PVP polymers. The presence of $\mathrm{Zn}^{2+}$ was detected in the compartment 3 using the different synthetic membranes. This is due to the fact that $\mathrm{Zn}^{2+}$ is not or weakly complexed by the polymers of M1, M2 and M3 membranes. The $\mathrm{Ni}^{2+}$ was not detected in the compartment 3, this is due to the fact that $\mathrm{Ni}^{2+}$ is complexed by thiourea in the second compartment.

\subsection{Transport of $\mathrm{M}^{2+}$ ions using a commercial membrane (titration in the compartments}

\section{2 and 3)}

For a comparative purpose, a commercial membrane-type cation exchange, CMS, was considered in the same experimental conditions, i.e. the same cell and same solutions. We note that this commercial membrane behaves in a quite similar manner for the three ions. Figure 8 show the amounts of metal transferred in the compartments 2 (a) and 3 (b) using the commercial CMS membrane. A change in the concentration was observed after $3 \mathrm{~h}$ of dialysis. Time-courses of the amount of metal transferred show that $\mathrm{Ni}^{2+}$ and $\mathrm{Cu}^{2+}$ were the most transferred ions using CMS commercial membrane in comparison with the three synthesized membranes.

\subsection{Photo-electrodialysis through the M1 membrane in the open cell}

The M1 membrane showed good ability in the separation of the three ions and hence was chosen for the photo-electrodialysis. The photo-electrode $\mathrm{FeAl}_{2} \mathrm{O}_{4}$ was placed in the first compartment while the inert steel counter electrode in the third compartment; therefore, the cell worked in a short circuit configuration.

\subsubsection{Effect of the concentration of the transferred metal}

Based on Figure 9, note that a significant amount of $\mathrm{M}^{2+}$ ions was transferred through the membrane $\mathrm{M} 1$ using $\mathrm{FeAl}_{2} \mathrm{O}_{4}$ as photoelectrode. Concerning the metal transfer and similarly to the trend observed in the absence of the photoelectrode, whatever the experimental conditions $\mathrm{Cu}^{2+}$ did not react favorably with the membrane $\mathrm{M} 1 . \mathrm{Zn}^{2+}$ migration from the first to the second compartment was very effective, since $33 \%\left(1.2 \times 10^{-3} \mathrm{~mol} \mathrm{~L}^{-1}\right)$ of 
the initial amount was transferred to the second compartment after $3 \mathrm{~h}$, without taking into account the transferred amount to the third compartment and that adsorbed by the two membranes. A concentration of $6 \times 10^{-4} \mathrm{~mol} \mathrm{~L}^{-1}$ was found in the third compartment at the end of the experiment. This shows the high selectivity of the membrane M1 in terms of photoelectrodialysis regarding $\mathrm{Zn}^{2+}$. $\mathrm{Ni}^{2+}$ and $\mathrm{Zn}^{2+}$ moved relatively at low rate, before a sharp increase in the concentration was recorded in the third compartment after $3 \mathrm{~h}$. It is worth noting that the composition of the membrane M1 (consisting of PEI and CTA in addition to the plasticizer) is likely to fix these metals to form stable amine complexes according to the sequence: $\mathrm{Cu}>\mathrm{Ni}>\mathrm{Zn}$. This is due to the saturation of the membrane by the metal-carrier complex molecules and the decomplexation at the strip interface is presumably the ratelimiting step in such process. Fujimori [33] revealed the existence of copper and nickel complex with PEI in the stoichiometry 3.2 and 3.7 for PEI:Cu and PEI:Ni, respectively. This is due to the geometry of the complex (square planar in the case of copper and octahedral for nickel). These complexes are more stable than the PEI:Zn. In Table 3 are reported the overall formation constants of the three complexes [34]. As it can be observed, the stabilities are involved in the order: PEI:Cu > PEI:Ni > PEI:Zn.

The best transfer for the three metal ions was obtained at a current density of $0.78 \mathrm{~mA} \mathrm{~cm} \mathrm{c}^{-2}$ and an initial concentration of $10^{-2} \mathrm{~mol} \mathrm{~L}^{-1}$.

\subsubsection{The effect of the potential}

The use of the semi-conducting photoelectrode is considered as a promising tool to generate an electrical gradient field to improve ions transfer. Indeed, the junction electric field generated under illumination substantially increases the diffusion flux of ions. Figure 10 shows the values of the generated potential over time, measured in parallel with a high impedance voltmeter $\left(10^{9} \Omega\right)$ via the two electrodes; it increased during the first 100 minutes and then remained almost stable.

\subsubsection{Variation of the conductivity and the $\mathrm{pH}$}

Along with determining the potential through the cell, both the conductivity and $\mathrm{pH}$ of the solutions of all compartments were monitored and the results are gathered in Figure 11.

Three distinct zones are visible in the graph of the conductivity. The first zone corresponds to the decrease of the conductivity over time up to $3 \mathrm{~h}$ of dialysis in the first compartment (feed compartment) can be explained by the movement of ions from the solution of a compartment to the inside of the membrane. The second zone corresponds to 
the second movement of ions or exchange that occurs into the membrane between its protons and ions $\mathrm{M}^{2+}$ of the solution. In the third zone, a slight decrease of the conductivity was observed, due to the hydrogen evolution, which was observed at the end of the experiment. The $\mathrm{H}_{2}$-liberation can be mainly attributed to the reactions of reduction of protons at the electrodes.

\section{Conclusion}

The possibility of using a less energy-consuming process for wastewater treatment was examined in this work. New polymeric membranes were implemented and tested in processes using ion exchange materials for the treatment of solutions of hydro-metallurgical industries; the ion exchange membrane is an essential part of the process. The membrane was successfully polymerized from cellulose triacetate noted (CTA) modified by poly-electrolytes and plasticized by (TEHP).

The obtained results showed that a developed membrane-based PEI was not selective with regard to $\mathrm{Cu}^{2+}$ but had a high affinity for $\mathrm{Ni}^{2+}$ transfer, followed by $\mathrm{Zn}^{2+}$. The transferred amount of $\mathrm{Zn}^{2+}$ was higher during photo-electrodialysis than in simple dialysis, so the developed PEI based membrane becoming more selective to $\mathrm{Zn}^{2+}$ under illumination. The best transfer for the three metal ions was obtained at a current density of $0.78 \mathrm{~mA} \mathrm{~cm}^{-2}$ and an initial concentration of $10^{-2} \mathrm{~mol} \mathrm{~L}^{-1}$. It has also been shown that the commercial membrane was selective to zinc in the closed cell, by cons in the open cell it was selective for copper.

This study may be continued by examining the nature of the medium $(\mathrm{pH}$, conductivity, temperature, etc. ...). Further efforts should be directed toward the determination of the nature of interactions between polymer and poly-electrolytes by the use of other materials and analytical tools as well. Other applications may also be planned for other objectives (biological, medical, environmental, ...etc). 


\section{References}

[1] B. Bansal, X. D. Chen, M. M. Hossain, Chem. Eng. Process. 44 (2005)1327-1336.

[2] L. D. Nghiem, P. Mornane, I. D. Potter, J. M. Perera, R. W. Cattrall, S. D. Kolev, J. Membr. Sci. 281 (2006) 7-41

[3] S. Bensaadi, M. Amara, O. Arous, H. Kerdjoudj, Desal. Wat. Treat. (2014) 1-7, DOI: 10.1080/19443994.2014.969315

[4] G. Crini, N. Morin-Crini, N. Fatin-Rouge, S. Déon, P. Fievet, Arab. J. Chem. (2014) http://dx.doi.org/10.1016/j.arabjc.2014.020.

[5] S. Bensaadi, O. Arous, H. Kerdjoudj, M. Amara, J. Env. Chem. Eng. 4 (2016) 1545-1554

[6] J.F. Dozol, M. Dozol, R.M. Macias, J. Incl. Phenomena Macrocycl. Chem. 38(2000)1-22.

[7] M. Amara, H. Kerdjoudj, Desalination, 168 (2004) 195-200

[8] P.K. Mohapatra, D.S. Lakshmi, V.K. Manchanda, Desalination 198(2006)166-172.

[9] M. Amara, H. Kerdjoudj, Desalination, 206, 1-3 (2007) 205-209

[10] Y. Berbar, M. Amara, H. Kerdjoudj, Desalination, 223, 1-3 (2008) 238-242

[11] R. A. Bartsch, J. Way, ACS Symposium Series 642, Washington DC, (1996) 575-579.

[12] M. Amara, H. Kerdjoudj, A. Bouguelia, M. Trari,. J. Membr. Sci. 312 (2008)125-131

[13] Amara M., Arous O., Smail F., Kerdjoudj H., Trari M., Bouguelia A., J. Hazard. Mater. 169 (2009) 195-202.

[14] Arous O., Amara M., Trari M., Bouguelia A., H. Kerdjoudj, J. Hazard. Mater. 180 (2010) 493-498.

[15] O. Arous, F. Saad Saoud, M. Amara, H. Kerdjoudj, Mater. Sci. App. 2 (2011) 615-623.

[16] A. Yahia Cherif, O. Arous, M. Amara, H. Kerdjoudj, Topics in Chem. Mater. Sci. 6 (2011) 98-105.

[17] A. Yahia Cherif, O. Arous, M. Amara, S. Omeiri, H. Kerdjoudj, M. Trari, J. Hazard. Mater. 227-228 (2012) 386-393.

[18] H. Yang, J. Yan, Z. Lua, X. Cheng, Y. Tang, J. Alloys Compd. 476 (2009) 715-719.

[19] J. Yan, H. Yang, Y. Tang, Z. Lu, S. Zheng, M. Yao, Y. Han, Renew. Energy 34 (2009) 2399-2403.

[20] K. Gurunathan, J.O. Baeg, S.M. Lee, E. Subramanian, S.J. Moon, K.J. Kong, Inter. J. Hydrogen Energy 33 (2008) 2646-2652.

[21] U. Russo, S. Carbonin, A.D. Giusta, in: G.J. Long, F. Grandjean (Eds.), Mossbauer Spectroscopy Applied to Magnetism and Materials Science, Plenum, New York,2 (1996) 207. [22] J. Smith, H.P. Wijn, Ferrites, John Wiley \& Sons, (1959) 
[23] N. Tristan, J. Hemberger, A. Krimmel, H.A. Krug von Nidda, V. Tsurkan, A. Loidl, Phys. Rev. B 72 (2005)174404-174413.

[24] P.M. Botta, R.C. Mercader, E.F. Aglietti, J.M. Porto Lopez, Scr. Mater. 48 (2003) 1093 1098.

[25] M. Sugiura, M. Kikkawa, S. Urita, J. Membr. Sci. 42 (1989) 47-55.

[26] M. Sugiura, Sep. Sci. Technol. 25 (1990) 1189-1199.

[27] M. Sugiura, Sep. Sci. Technol. 28 (1993) 1453-1463.

[28] B. Chakrabarty, A.K. Ghoshal, M.K. Purkait, J. Membr. Sci. 315(2008)36-47.

[29] W.L. Chou, D.G. Yu, M.C. Yang, C.H. Jou, Separ. Purif. Tech. 57(2007)209-219

[30] B. Chakrabarty, A.K. Ghoshal, M.K. Purkait, J. Membr. Sci. 309(2008)209-221

[31] E.W. Nuffield, X-ray Diffraction Methods, John Wiley \& Sons, 1966.

[32] A. Ammi Said, M. Amara, H. Kerdjoudj, IONICS, 19(2013)177-183.

[33] K. Fujimori, J. Polym. Sci. Chem. 23 (1985) 169-174.

[34] V.H. Thiele, K.H. Gronau, Makromol. Chem. 59 (1963) 207. 


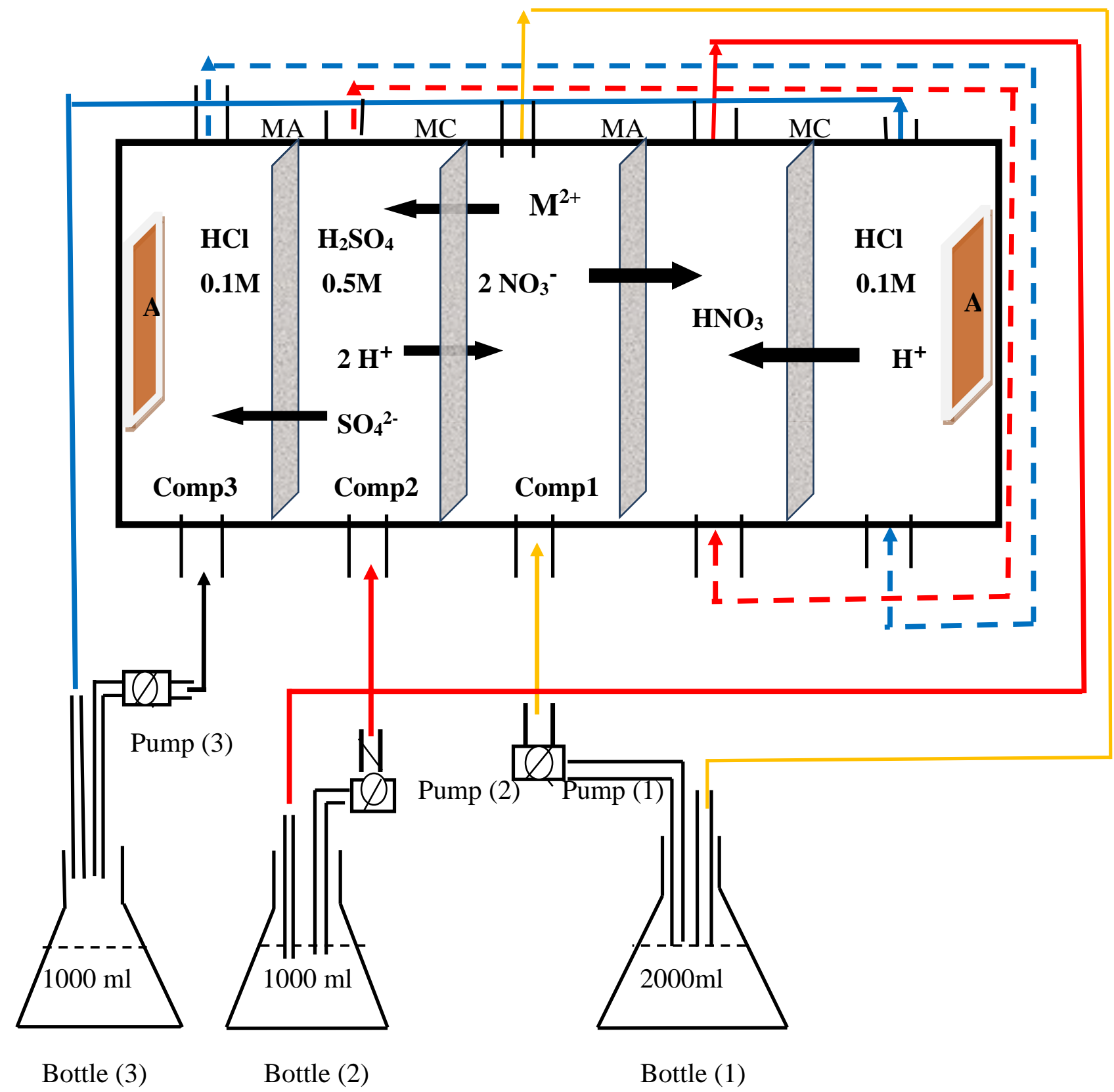

Figure 1. The device of closed cell with the capacity of the various compartments AM: anionic membrane; CM: cationic membrane; A: electrode 


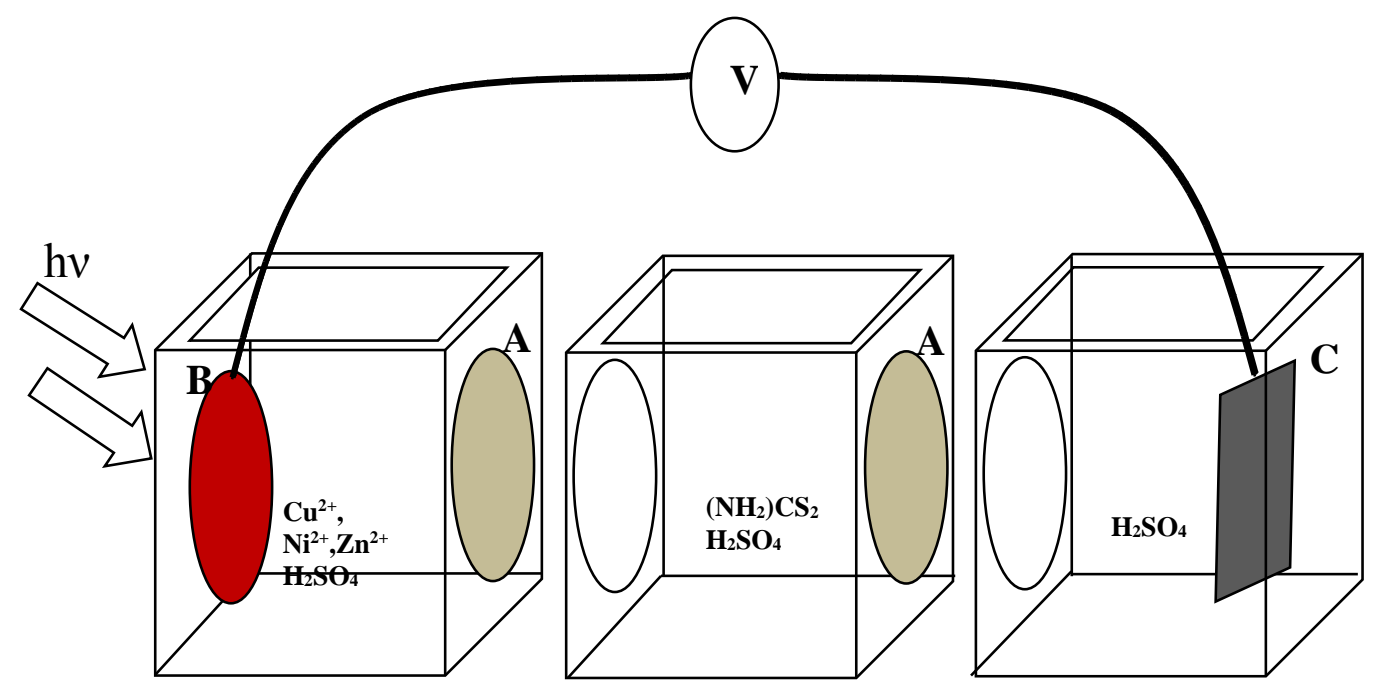

Figure 2. Transport cell scheme: A: Synthetic membrane; $\mathbf{B}: \mathrm{FeAl}_{2} \mathrm{O}_{4}$ electrode; $\mathbf{C}$ : platinum electrode 


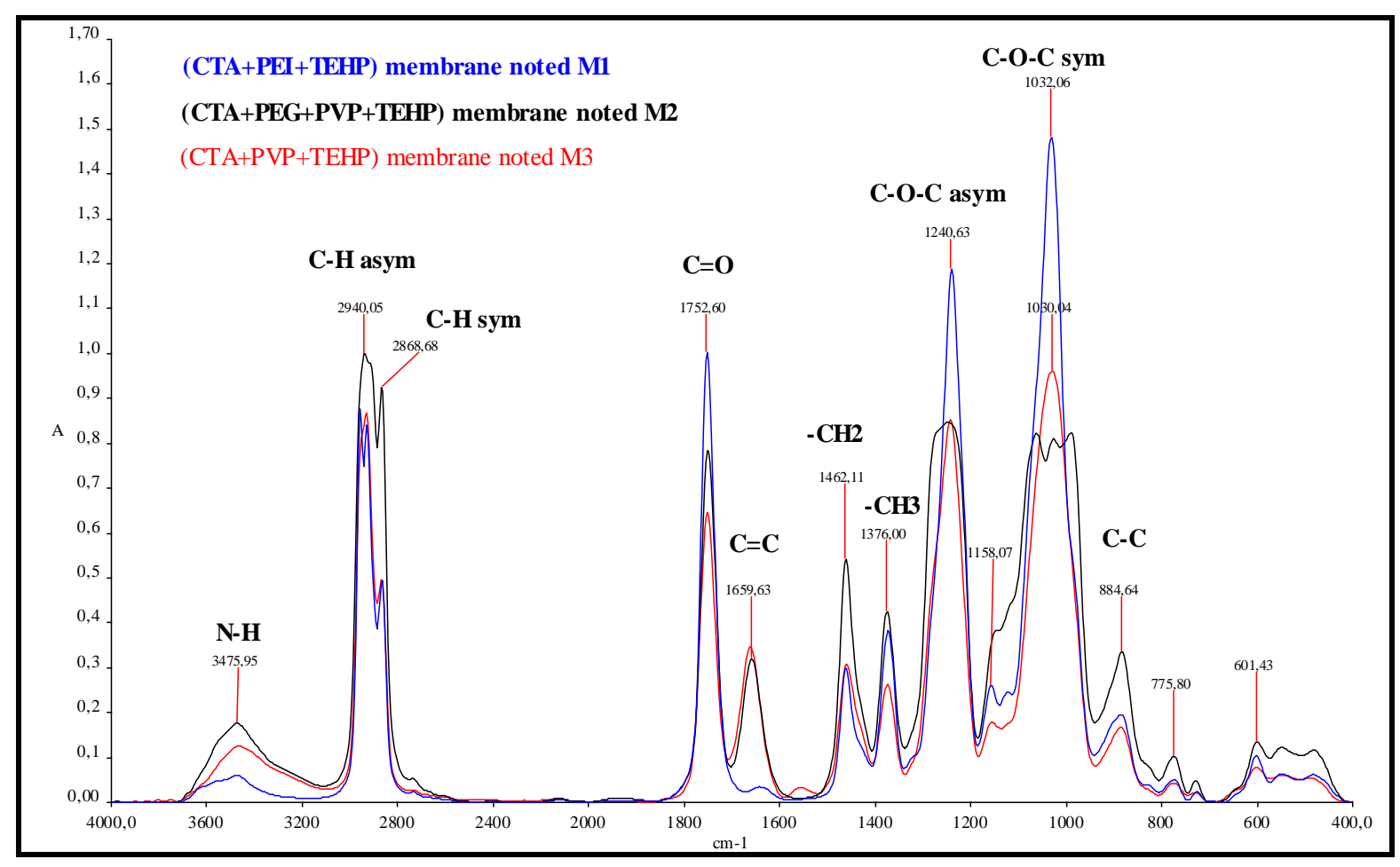

Figure 3. FTIR spectra of M1, M2 and M3 membranes. 


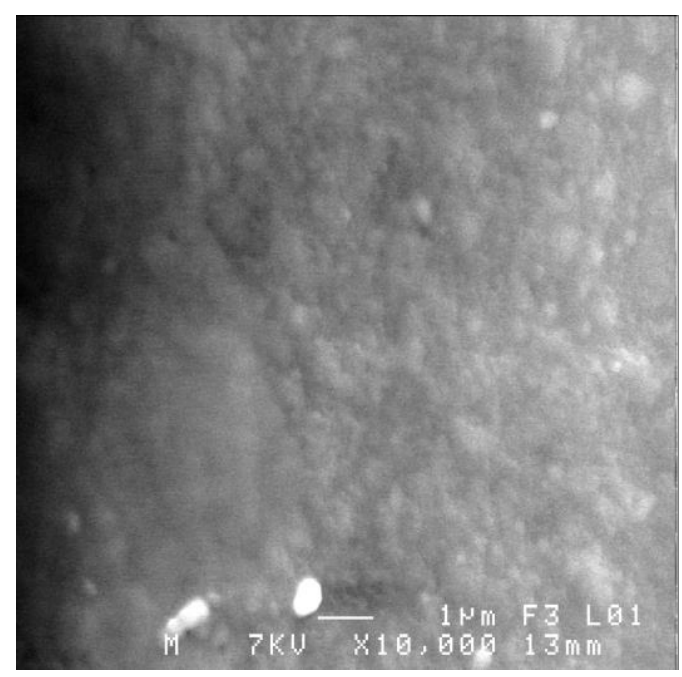

a) membrane M1

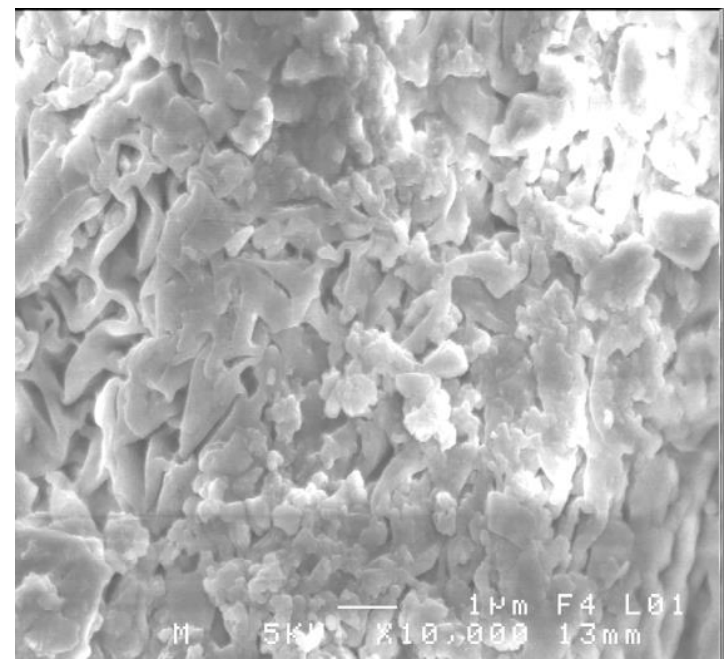

c) membrane M3

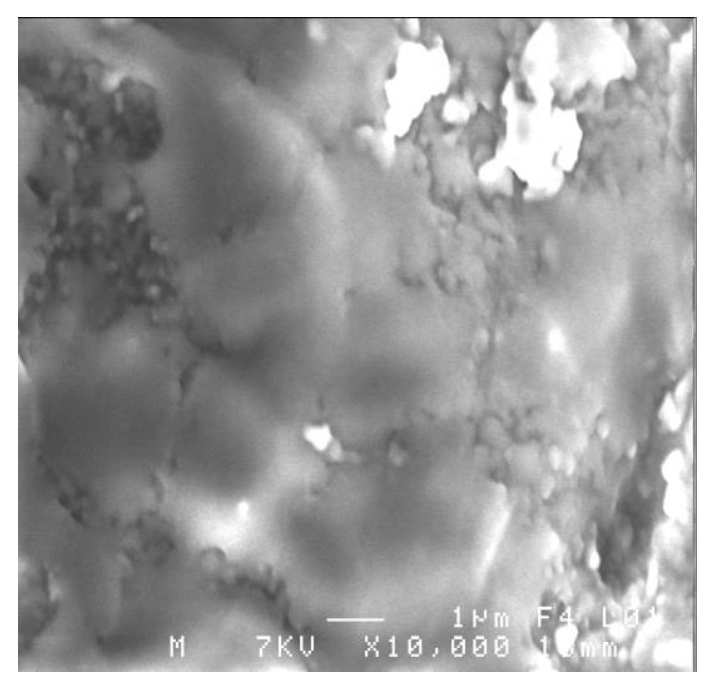

b) membrane M2

Figure 4. SEM Images of M1 (a), M2 (b) and M3 (c) membranes. 


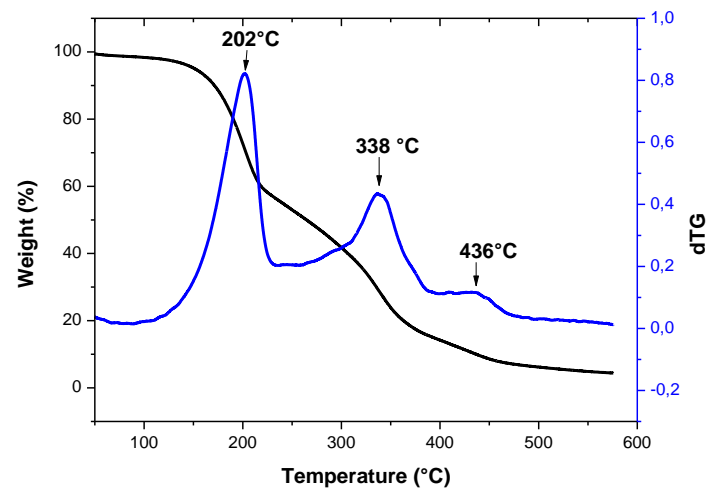

a) membrane M1

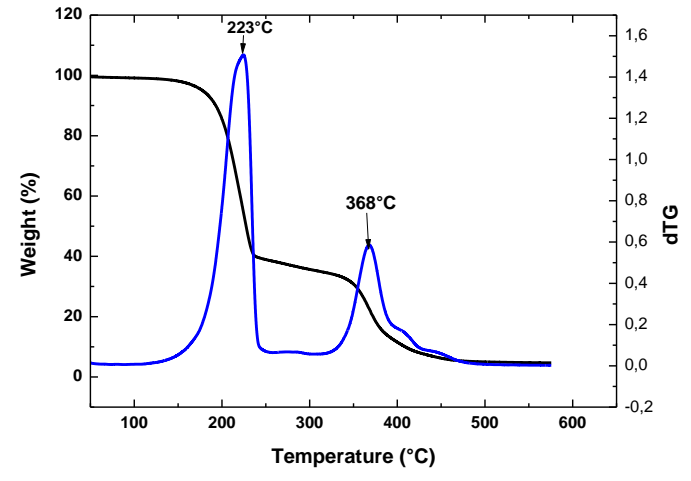

b) membrane M2

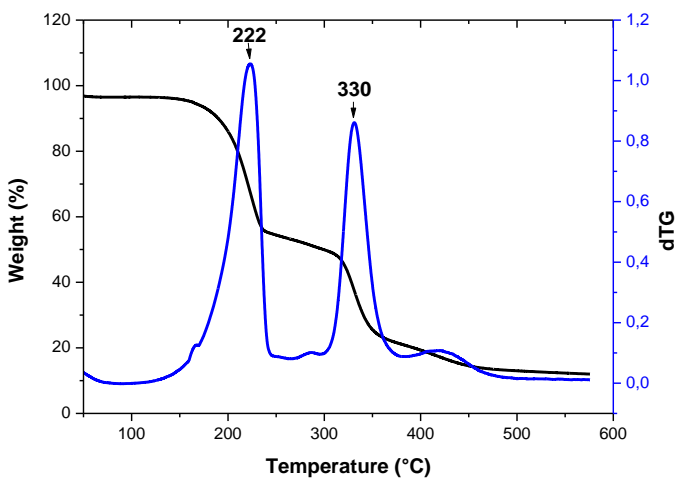

\section{c) Membrane M3}

Figure 5. Thermograms ATG/dTG of M1 (a), M2 (b) and M3 (c) membranes. 


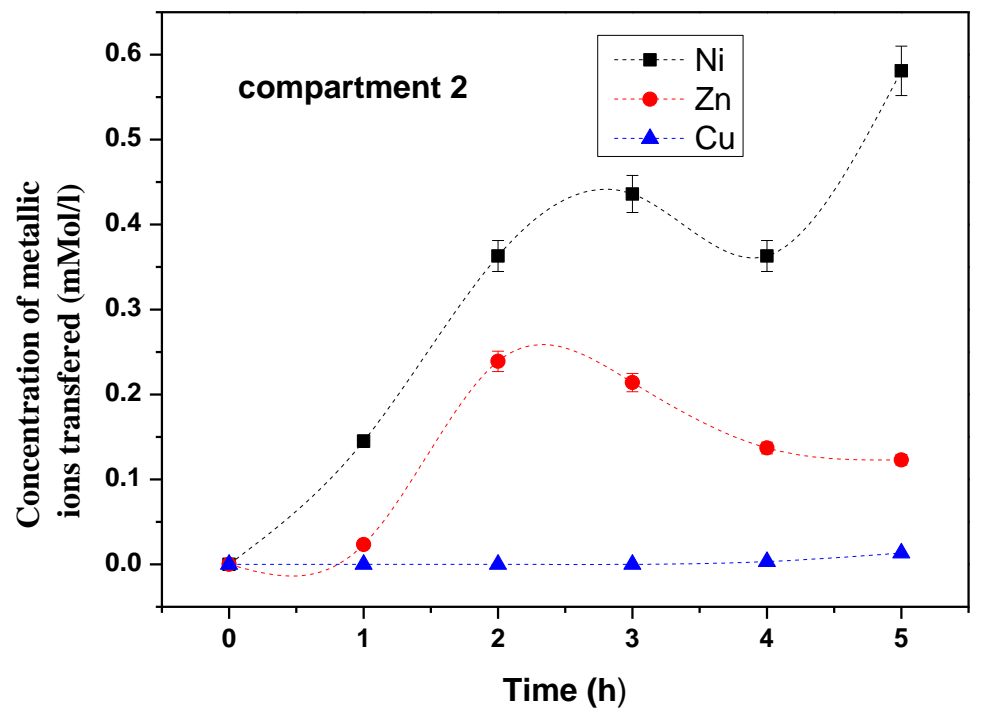

(a)Membrane M1

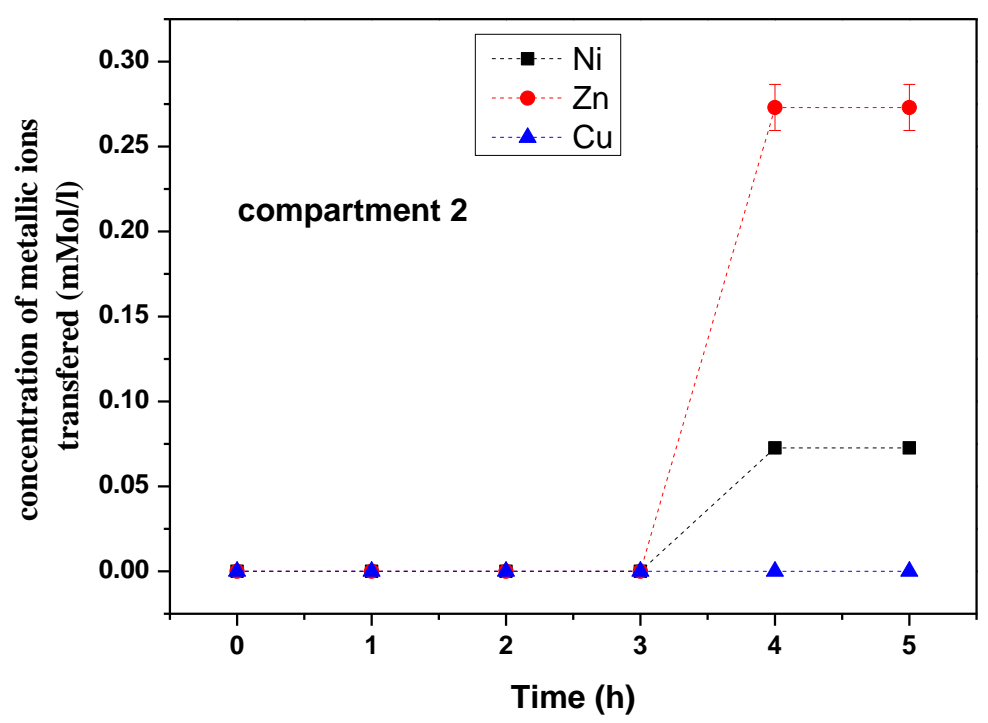

(b)Membrane M2 


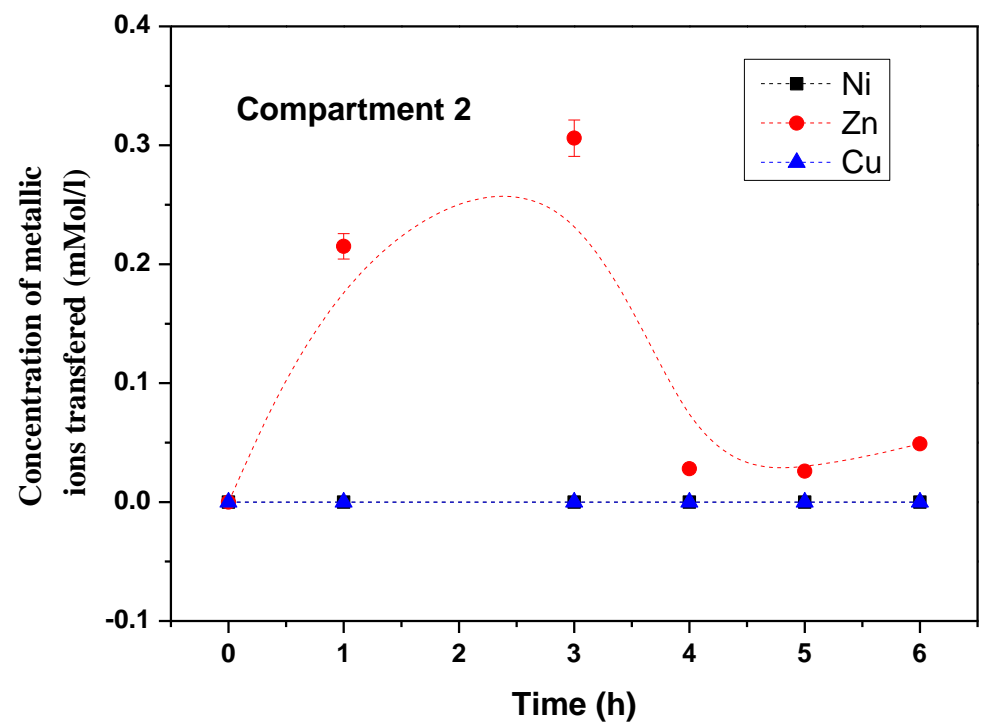

\section{(c)Membrane M3}

Figure 6. Concentration of metallic ions transferred in the second compartment versus time using the three synthesized membranes. $\left(\left[\mathrm{M}^{2+}\right]_{\mathrm{o}}=10^{-2} \mathrm{~mol} \mathrm{~L}^{-1}, \mathrm{~T}=20^{\circ} \mathrm{C}\right)$ 


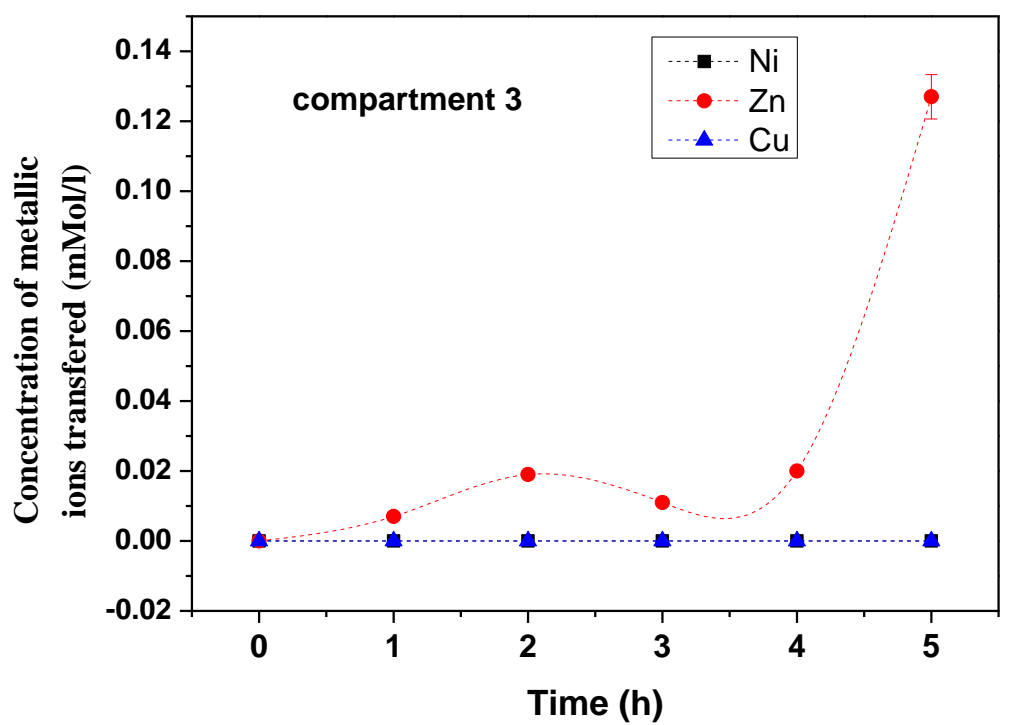

(a) Membrane M1

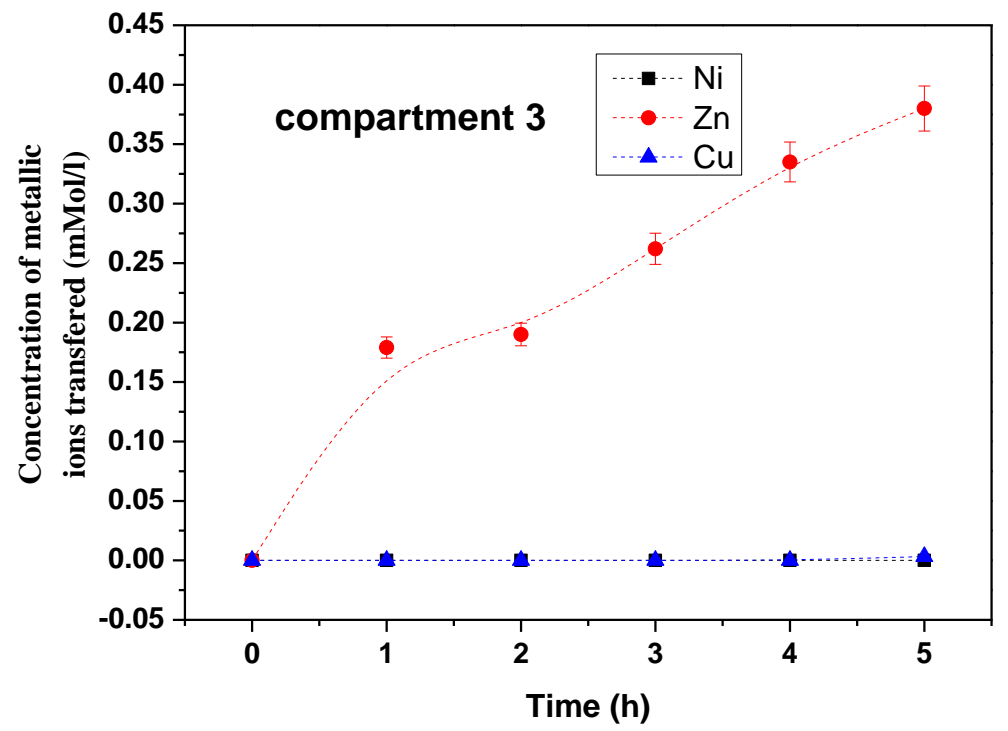

(b) Membrane M2 


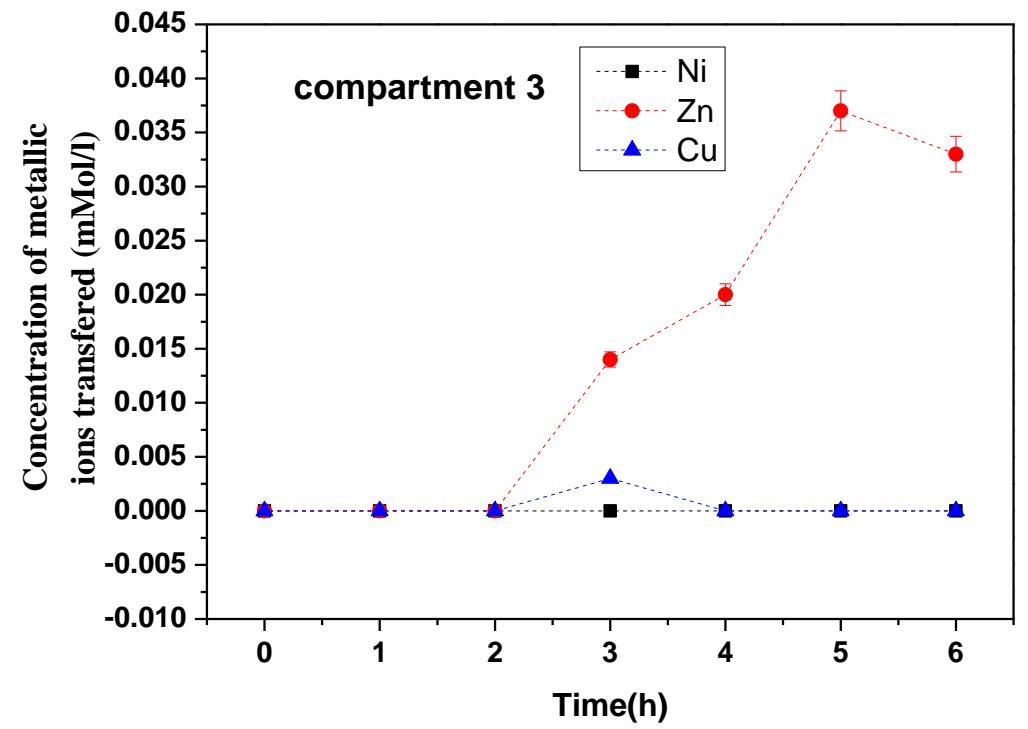

(c) Membrane M3

Figure 7. Concentration of metallic ions transferred in the third compartment versus time using the three synthesized membranes. $\left(\left[\mathrm{M}^{2+}\right]_{\mathrm{o}}=10^{-2} \mathrm{~mol} \mathrm{~L}^{-1}, \mathrm{~T}=20^{\circ} \mathrm{C}\right)$ 


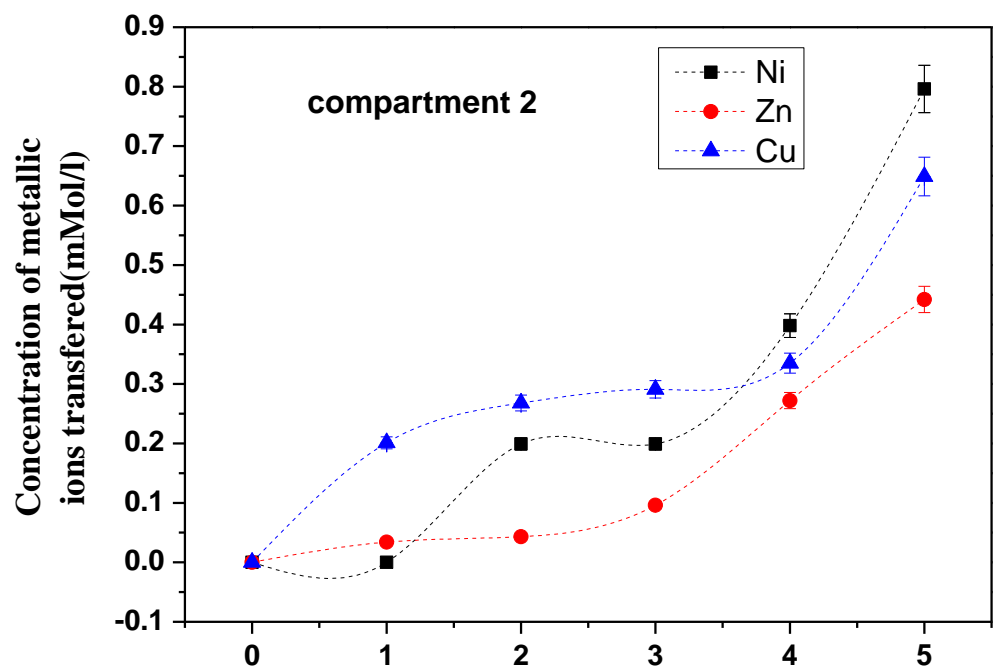

(a)

Time (h)

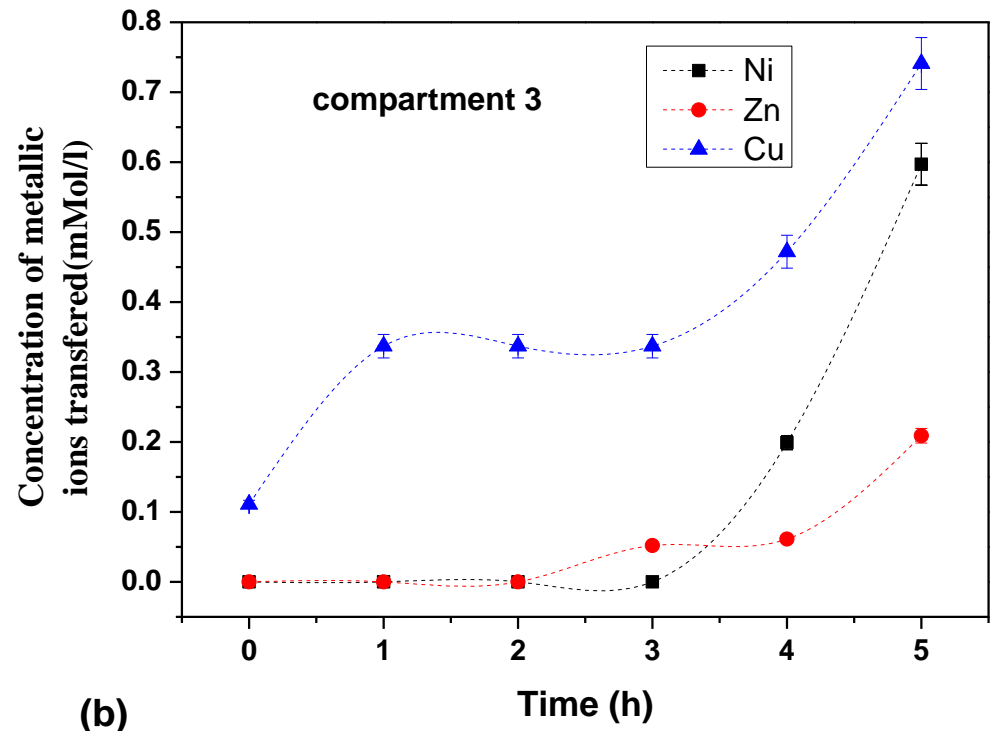

Figure 8. Amounts of metal transferred in the compartments 2 (a) and 3 (b) versus time using the commercial CMS membrane. $\left(\left[\mathrm{M}^{2+}\right]_{\mathrm{o}}=10^{-2} \mathrm{~mol} \mathrm{~L}^{-1}, \mathrm{~T}=20^{\circ} \mathrm{C}\right)$ 


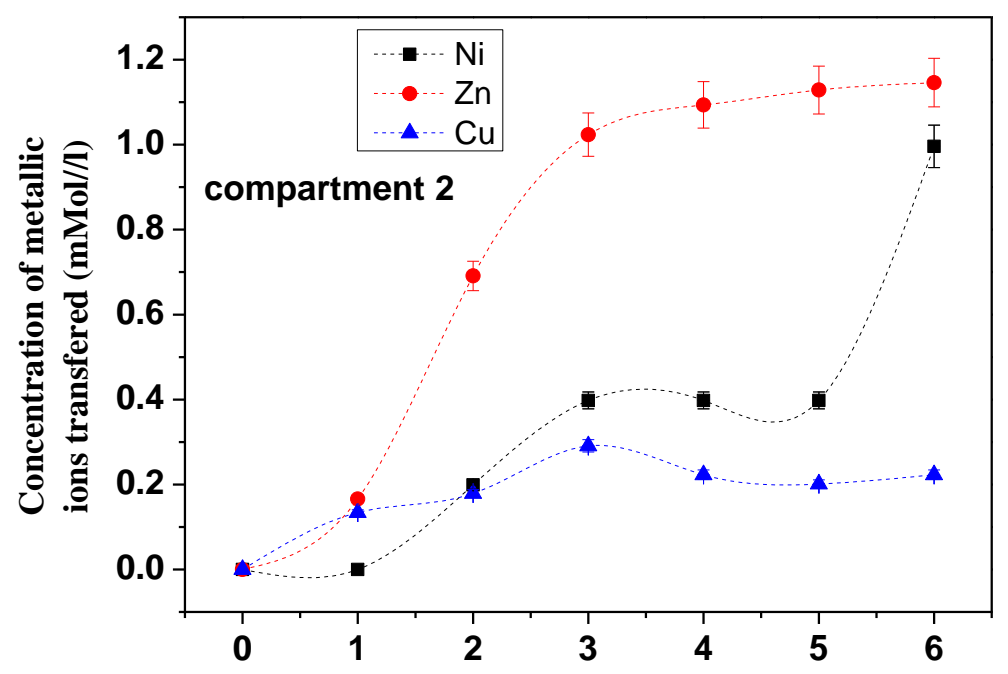

(a)

Time (h)

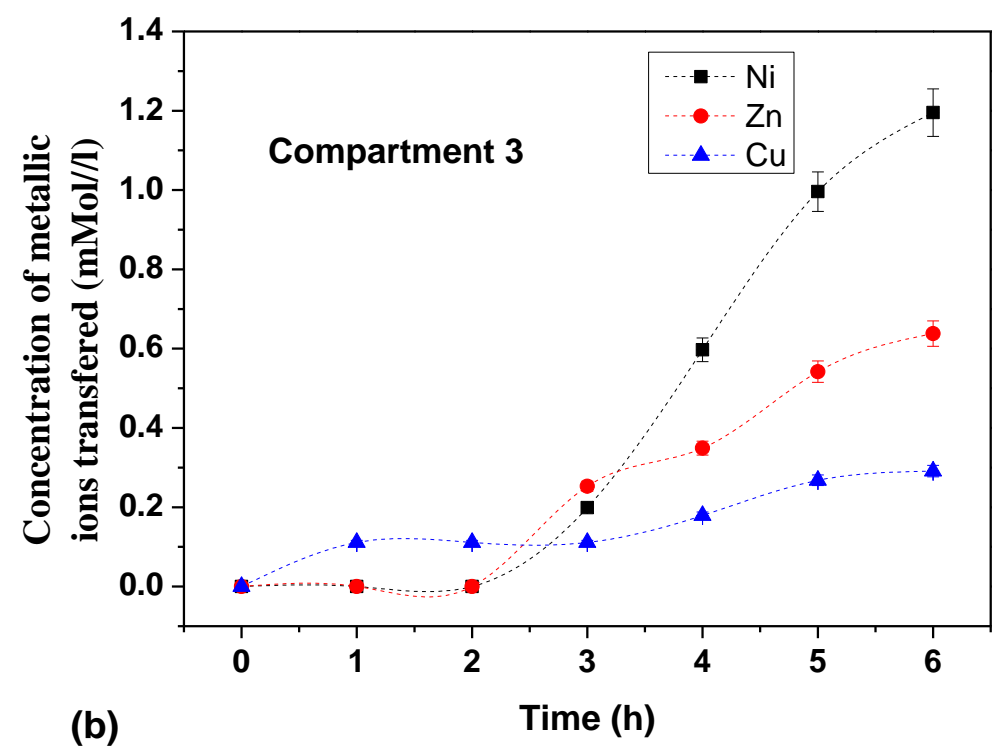

Figure 9. Time-courses of the amount of metal transferred in the compartments 2 (a) and 3 (b) using the M1 membrane. $\left(\left[\mathrm{M}^{2+}\right]_{\mathrm{o}}=10^{-2} \mathrm{~mol} \mathrm{~L}^{-1}, \mathrm{~T}=20^{\circ} \mathrm{C}\right)$ 


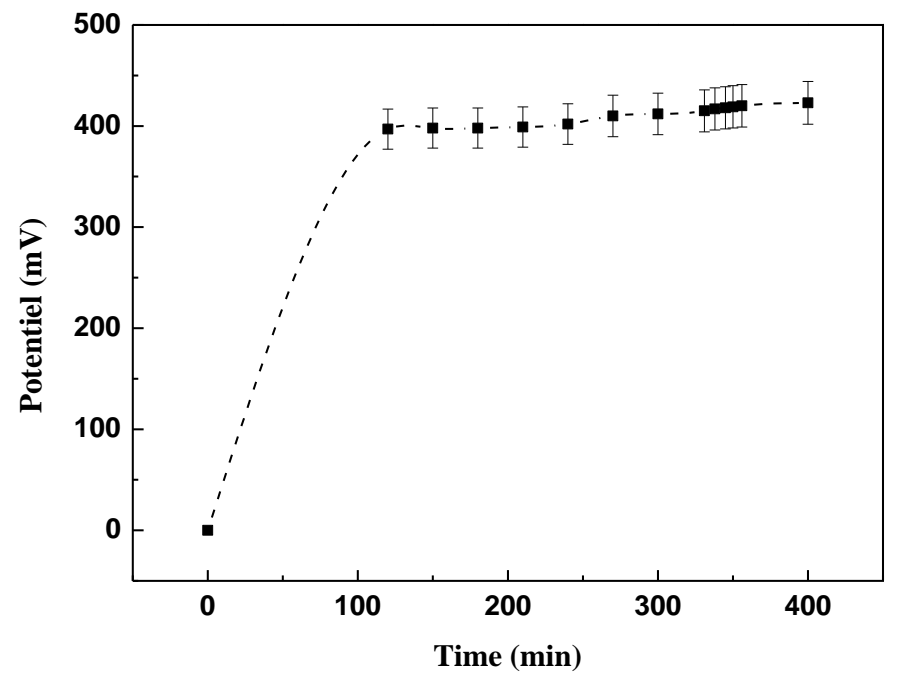

Figure 10. The potential created in the photo-electrodialysis system versus time using the membrane M1 

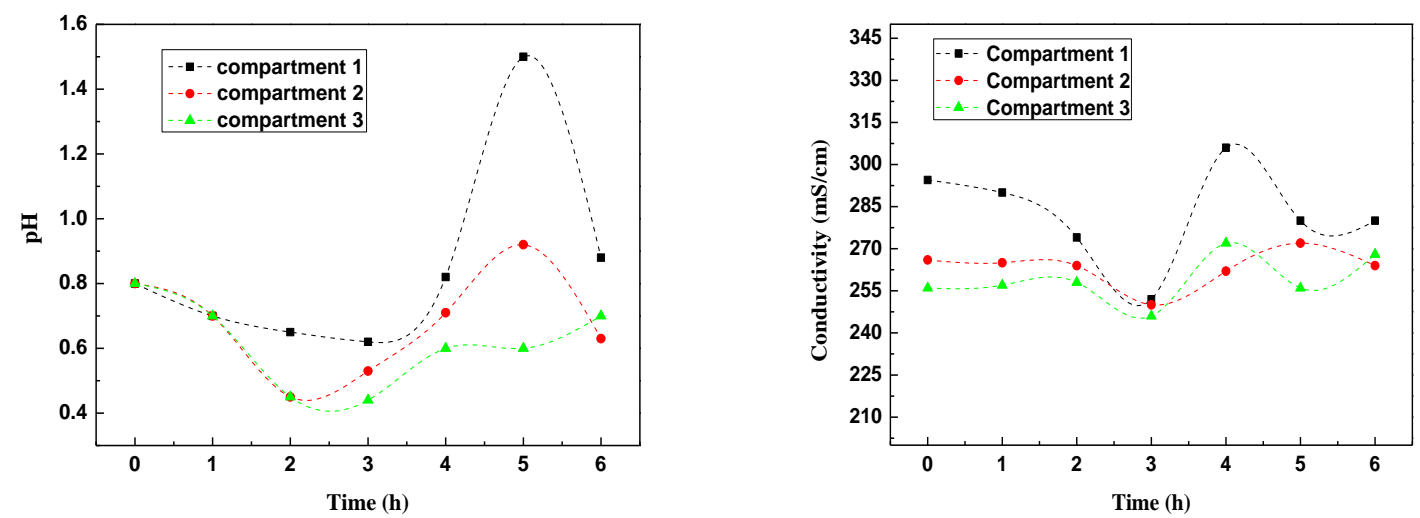

Figure 11. The change in $\mathrm{pH}$ and conductivity in the three compartments as a function of time during photo-electrodialysis using the membrane $\mathrm{M} 1 .\left(\left[\mathrm{M}^{2+}\right]_{\mathrm{o}}=10^{-2} \mathrm{~mol} \mathrm{~L}^{-1}, \mathrm{~T}=20^{\circ} \mathrm{C}\right)$ 
Table 1: Physical Parameters of $\mathrm{FeAl}_{2} \mathrm{O}_{4}$

\begin{tabular}{llll}
\hline Oxyde & $\rho_{\exp }\left(\mathrm{g} / \mathrm{cm}^{3}\right)$ & $\mathrm{S}_{\mathrm{sp}}$ & $\mathrm{d}$ \\
\hline $\mathrm{FeAl}_{2} \mathrm{O}_{4}$ & 3.83 & 8.584 & 0.1825 \\
\hline
\end{tabular}


Table 2: Physical characteristics of the synthesized membranes.

\begin{tabular}{llll}
\hline Membrane & $\begin{array}{l}\text { thickness } \\
(\boldsymbol{\mu m})\end{array}$ & $\begin{array}{l}\text { contact } \\
\text { angle }\left(^{\circ}\right)\end{array}$ & $\begin{array}{l}\text { Density } \\
\left(\mathbf{m g} / \mathbf{c m}^{2}\right)\end{array}$ \\
\hline CTA & 10 & 46.42 & 4.478 \\
CTA+TEHP & 12 & 75.81 & 5.084 \\
(CTA+ PEI+ TEHP) noted M1 & 32 & 64.55 & 5.219 \\
(CTA+ PEG+ PVP+TEHP) noted M2 & 35 & 65.12 & 5.628 \\
(CTA+ PVP+ TEHP) noted M3 & 30 & 66.43 & 2.830 \\
\hline
\end{tabular}


Table 3. Overall stability constant for the PEI-metal complex.

\begin{tabular}{llll}
\hline & PEI:Cu & PEI:Ni & PEI:Zn \\
\hline $\log$ K & 11.1 & 10.8 & 10.2 \\
\hline
\end{tabular}




\section{Appendix}

Table : Physical and Chemical characteristics of the CMS commercial membrane according to Neosepta.

\begin{tabular}{|l|l|l|}
\hline Memebrane & $\begin{array}{l}\text { CMS Neosepta (Japan) } \\
\text { Cationic Exchange Membrane }\end{array}$ & $\begin{array}{l}\text { ACM Asahi Glass (japon) } \\
\text { Anionic Exchange Membrane }\end{array}$ \\
\hline Polymer & Polystyrene-Di-vinyl benzene & - \\
\hline Water Content $(\%)$ & 13.9 & 28 \\
\hline Membrane Thickness $(\mu \mathrm{m})$ & 122 & 133 \\
\hline Electrical Resistance $\left(\Omega \mathrm{cm}^{2}\right)$ & $2.5-3.5$ & - \\
\hline Transport Number & $\geq 0.98$ & - \\
\hline Exchange Capacity $\left(\mathrm{meq}_{\mathrm{g}} \mathrm{g}^{-1}\right)$ & 2.30 & 2.40 \\
\hline
\end{tabular}

